\title{
Phlebotomy, a bridge between laboratory and patient
}

\author{
Cristiano lalongo ${ }^{* 1}$, Sergio Bernardini ${ }^{1,2}$ \\ ${ }^{1}$ Laboratory Medicine Department, "Tor Vergata" University Hospital, Rome, Italy \\ 2Experimental Medicine and Surgery Department, "Tor Vergata" University, Rome, Italy \\ *Corresponding author: cristiano.ialongo@gmail.com
}

\begin{abstract}
The evidence-based paradigm has changed and evolved medical practice. Phlebotomy, which dates back to the age of ancient Greece, has gained experience through the evolution of medicine becoming a fundamental diagnostic tool. Nowadays it connects the patient with the clinical laboratory dimension building up a bridge. However, more often there is a gap between laboratory and phlebotomist that causes misunderstandings and burdens on patient safety. Therefore, the scope of this review is delivering a view of modern phlebotomy to "bridge" patient and laboratory. In this regard the paper describes devices, tools and procedures in the light of the most recent scientific findings, also discussing their impact on both quality of blood testing and patient safety. It also addresses the issues concerning medical aspect of venipuncture, like the practical approach to the superficial veins anatomy, as well as the management of the patient's compliance with the blood draw. Thereby, the clinical, technical and practical issues are treated with the same relevance throughout the entire paper.
\end{abstract}

Key words: phlebotomy; venipuncture; laboratory testing; preanalytical phase; preanalytical variability; patient safety; evidence based medicine

\section{Introduction: Historical and etymological perspective}

Medicine has considerably changed over the years. Since the age of Hippocrates and Galen, through the evidence-based paradigm, many medical practices have been renewed. However, some of them, thanks to more advanced devices, have been improved but not changed, such as phlebotomy, a kind of "prehistoric survivor".

The term phlebotomy comes from ancient Greek, and literally means "lancing (tomia from témno) a vein (fléba from flés)". Sensu strictu, it indicates the practice of causing a loss of blood (bloodletting) for therapeutic purposes (1). In this respect, the term "venipuncture" is considerably more recent, since it refers to the practice of drawing blood (by penetrating the vein's wall with a needle rather than cutting it with a lancet) for collection and analyses. Nowadays the terms phlebotomy, venipuncture and blood draw are synonymous. In the present paper these terms will be used interchangeably for our convenience. However, the first should be used to generally address any procedure which involves the iatrogenic accessioning to the vein lumen, the second for special cases in which the procedure is performed by means of a needle, and the third for vein accessioning aimed to blood collection. Notwithstanding that, the term phlebotomist is suitable to designate the operator in all of the aforementioned situations.

If we compare ancient phlebotomy versus modern venipuncture, we found a clear relationship with modern medicine. In the past phlebotomy was essentially a therapeutic resource to cure many ailments, whereas nowadays it is the diagnostic basis which medicine relies on to approach most of the known diseases $(1,2)$. Surprisingly, though centuries have passed and paradigms have changed, 
medicine seems unable to leave this practice out of consideration.

Due to the relevance gained by phlebotomy for the modern laboratory professionals, the purpose of this review is to deal with this practice in the light of the most recent findings. Our aim is also to raise the awareness of the curtain which very often separates laboratories and phlebotomists, unavoidably opposing excessively theoretical to extremely practical approaches to common issues. This divide inevitably involves patient safety which relies on both of these professionals. Therefore, we propose an approach for laboratory professionals by including all the criticalities proper of this craft.

The review will guide the reader through the procedure of phlebotomy, introducing at first basic tools of the phlebotomist (needle, tourniquet, blood collection system and disinfectant), and addressing their choice and the way they impact the reliability of blood testing. Secondly we will discuss the compliance of the patient to the blood draw, and the way to approach and manage it with respect to the success of the procedure and the safety of the individual. Thirdly we will describe the anatomy of the superficial veins, the identification of the most suitable site of phlebotomy, as well as the issues related to vein accessioning. Finally, in the last paragraph we will illustrate by a preanalytical standpoint how the various steps of the blood draw can be associated with erroneous blood testing results.

\section{The (good) phlebotomist's tools}

The basic tools for venipuncture are represented by the tourniquet, the needle with the blood collection device and the stick squeezed by the patient to dilate the veins (which is no longer in use). The needle and the blood collection device represent the tools that have undergone a considerable evolution through the years, and which will be discussed in detail later on. An overview on venipuncture is provided in Table 1.

For drawing blood by venipuncture, a needle with hollow shaft is used (Figure 1A) (3). Because the needle's tip has a cutting sharp bevel end with a concentric hole, it pierces the skin and breaches the vein wall, so that it is often defined as "epicranial" (which means "on the edge of the head" with respect to the hole position) or "hypodermal" (which means "under the skin" with respect to the penetration depth). Epicranial needles are made of stainless-steel, and differ in the length and gauge (G) of the shaft, with smaller values indicating larger diameters (4). Usually, in adult populations with regular veins, a $21 \mathrm{G}$ needle, which corresponds to $0.82 \mathrm{~mm}$ outer diameter and $0.51 \mathrm{~mm}$ inner diameter shaft on average, is used for venipuncture. The $23 \mathrm{G}$ needle, which corresponds to $0.64 \mathrm{~mm}$ outer diameter and $0.34 \mathrm{~mm}$ inner diameter shaft on average, is instead a better choice for paediatric venipuncture or in case of small and fragile veins. Epicranial needles can range in length between $1.9 \mathrm{~cm}$ and $5.1 \mathrm{~cm}$ on average, but $4 \mathrm{~cm}$ long needles are usually used for routine venipuncture with the shaft inserted for about $2 \mathrm{~cm}$ into the tissues (5).

There are two kinds of needles for phlebotomy, which can be recognized by their manufacturing, and in turn by the mode of action through which they are inserted (4). A regular or "straight" needle is represented by a metallic hollow shaft with a small body through which it connects to the blood collecting device. Hence, the insertion depends on an indirect mode of action, and how the handler directs the needle. Conversely, the so-called winged or "butterfly" has its own body provided with a pair of wing-like flexible tabs and PVC tubing that connects to the collecting device. The wings can be bended upward becoming a handle for the needle during insertion, and then can be flattened on patient's skin to stabilize the shaft once it lies within the vein (Figure 1B). Therefore, the insertion depends on a direct mode of action, as the needle is handled regardless of the collecting device. Noteworthy, the wings provide a means to secure the needle's body to the patient's skin with strips of adhesive tape or transparent membrane dressings. This makes it possible to use the winged needle also to infuse solutions, although for short periods due to the stiff metallic shaft which can harm the vein with its sharp end. Due to the connecting tubing the void volume of 
TABLE 1. Routine venipuncture at glance.

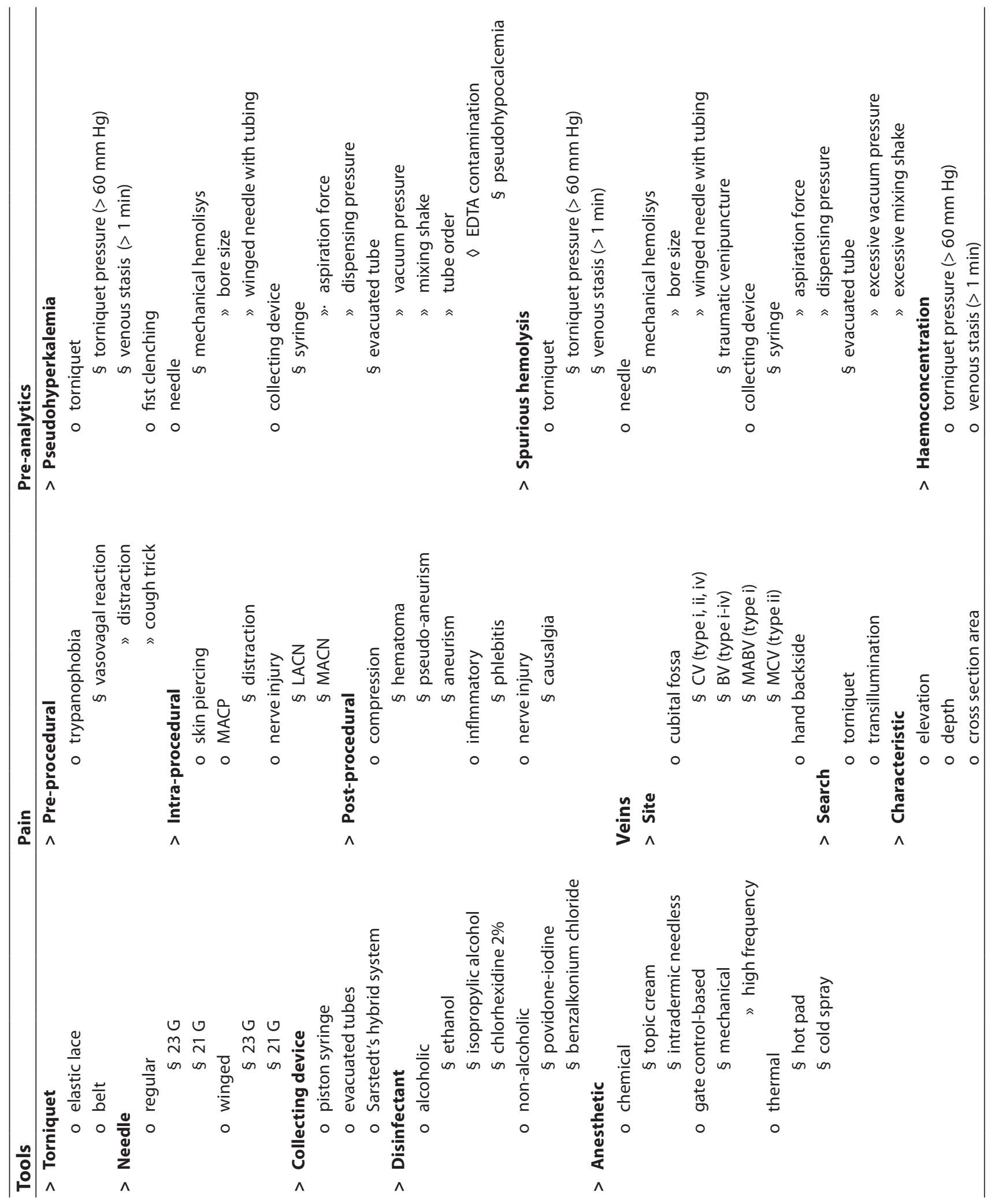

Roots $(>)$ are main topics, branches (o) are relevant issues and sub-items $(\S, », \diamond)$ are details.

MACP - motivational anticipatory cortical process; LACN - lateral antebrachial cutaneous nerve; MACN - medial antebrachial cutaneous nerve; CV - cephalic vein; BV - basilic vein; MABV - median antebrachial vein; MCV - median cubital vein. Variations in vein distribution and connections are classified as types i to iv (see Figure 3). 


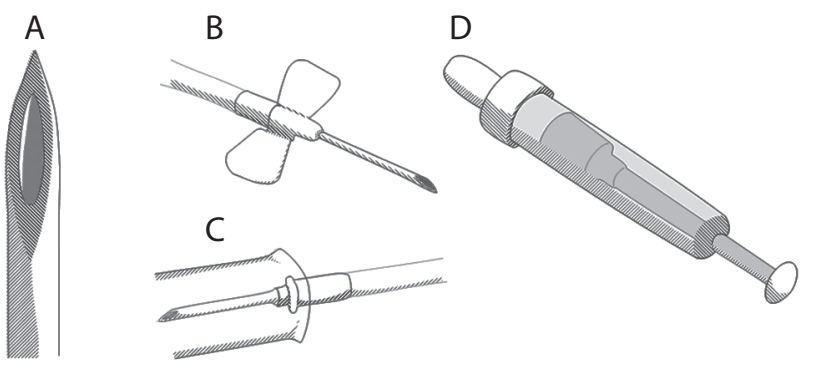

Figure 1. A) The piercing needle used for venipuncture has a stainless-steel hollow shaft with a concentric hole on the bevel end; B) a winged needle or "butterfly" has a pair of winglets attached at the base of the shaft, that fold for handling or lay flat for stabilization, and a connection tubing which carries the blood to the collecting tube; $C$ ) the dispensing needle, which is fixed into the inner side of tube holder, pierces the rubber stop of the tube allowing the blood to be drawn; D) the Sarstedt's hybrid system has a collecting tube with a plunger that can be used to withdrawn the blood during venipuncture or pulled before to evacuate the tube.

the collecting device is increased. Consequently, especially with large $G$ needles, the time blood flow spends to reach the additives is prolonged, activating platelets and leukocytes (6). However, with large bore size needles (like $21 \mathrm{G}$ ) the PVC tubing does not affect significantly the quality of laboratory testing (6). Moreover, if properly unfolded and held, the connecting tubing attenuates the involuntary movements of the needle inserted in the vein, which are due to pulling the plunger or switching the evacuated sampling tube into the holder $(5,7)$. The needles can have a retractile, sliding or a safety shield system to secure the blood shaft once extracted from the patient's skin (8). Such security systems are of great relevance for the phlebotomist, in that the needle recapping reduces to a sensible risk (odds ratio 1.78, 95\% confidence interval $1.11-2.86$ ) of percutaneous injuries. Noticeably, the adoption of medical devices incorporating safety-engineered protection mechanisms is explicitly required by the European Council Directive on the prevention of sharps injury in the health care sector (Directive 2010/32/EU) (9). The main collecting devices are the piston syringe and the evacuated-tube system (4). A piston sy- ringe is a simple device in use since the second half of the $19^{\text {th }}$ century. It is made with a plunger that draws the blood into a barrel, to which the needle can be directly locked This system helps to measure the strength applied to draw blood, preventing collapsing veins or rupture in case of fragility. However, the barrel contains no additives, and it is disadvantageous as the drawn blood has to be successively dispensed into the tubes containing the specific additives. The evacuated-tube system is a more recent device introduced by Beckton and Dickinson in 1949 under the trade name of Vacutainer ${ }^{\top M}$ (formerly Evacutainer). In such a system the plunger is absent, and the barrel is replaced by a plastic or glass tube sealed with a rubber stop provided with preformed vacuum (10). By an adaptor it is possible to collect the blood directly in tube in which the required additive is already included. This is achieved by means of a needle which is in the tube holder and that pierces the rubber stop of the evacuated tube (Figure 1C). After drawing blood, the pierce in the rubber stop is resealed when the tube is removed from the holder, thus preventing the sample from leaking out. If the blood testing demands different additives, this system allows switching between multiple tubes without interrupting the blood withdrawal. The colour-code used for the tube stop guides the operator to choose the appropriate additive (11). The evacuated tubes system grants a higher safety for the operator and its environment because the blood specimen always circulates in a closed system $(12,13)$. It also ensures the quality of many lab tests avoiding the mechanical stress of the blood components produced by the dispensing, and ensuring to fill the tube with the appropriate quantity of blood for the required additive. As for the collecting devices, it is noteworthy to mention a third kind represented by the hybrid collecting system introduced by Sarstedt in 1975 and distributed under the trade name of SMonovette $^{\mathrm{TM}}$ (14). In such a device the collecting tube has a plunger which can be pulled during venipuncture to withdraw blood as in a typical syringe (Figure 1D). Alternatively, in order to use it as an evacuated tube, the plunger can be pulled and locked before venipuncture leaving a vacuum 
within. Since the tube includes an additive, there is no need of dispensing the blood afterwards. The Sarstedt's system is highly flexible, as it allows choosing the collecting technique according to the specific characteristic of the patient. This feature reduces significantly the incidence of haemolysis, allowing halving the rate of unsuitable samples even in a critical setting like the emergency department $(15,16)$. We would like to point out that even with evacuated tubes and hybrid systems a cross-contamination between different additives can happen if the device is not correctly used (as discussed in the last section of this paper).

Another topic which deserves a discussion in this section concerns the disinfectant, a basic but essential tool for the phlebotomist. Skin disinfection can be carried out using diluted alcoholic solutions (ethanol or isopropyl alcohol at 70\%), aqueous or alcoholic chlorhexidine solutions or aqueous povidone-iodine solution (17-19). All these agents, or their various combinations, are effective for venipuncture, nevertheless their appropriateness depends on collected kind of samples. Thus, non-alcoholic solutions should be preferred when performing a blood alcohol test whereas alcoholic solutions (especially those with chlorhexidine) should be used for blood cultures (20-22). However, the avoidance to use alcoholic solutions for blood alcohol test seems to be quite controversial, since some authors have shown that swabbing the venipuncture site with $70 \%$ isopropyl alcohol or ethanol does not significantly alter the blood alcohol level (23-25). In this regard, it should be said that alcohol tends to evaporate quite rapidly from the skin, reducing the quantity applied of about $50 \%$ within 10 seconds (26). Hence, it is likely that contamination may be due to an incorrect procedure, like the excessive wetting of the skin, a too early piercing before the evaporation of the disinfectant, or the needle withdrawal with the alcohol-soaked swab pressed over the puncture site and the evacuated tube still connected (27). Thus, non-alcoholic disinfectants would prevent the false-positive testing regardless of the correctness of the venipuncture procedure. It is noteworthy addressing the role of alcoholic skin disinfectants for percutaneously blood drawn cultures. Alcohol exerts its strong disinfectant activity by denaturing proteins, thus it has a broad range of antimicrobial activity except for spores. The evaporation shortens the duration of this antiseptic effect, nonetheless this is enough to prevent the bacterial carryover due to the skin piercing (28). Regardless of the disinfectant used (alcoholic, aqueous or mixed), contamination is most likely a consequence of the poor compliance to the established procedure, the choice of an unsuitable site or the device used to collect blood (29-31). This is remarkable, as the use of 70\% isopropyl alcohol solution is highly cost-effective and ensures the suitability of percutaneously drawn blood samples.

We would finally advise that to effectively reduce contamination, the phlebotomist's hands hygiene (washing and wearing gloves) is essential as much as the patient's appropriate skin cleansing. This has been shown by the rate of bacterial contamination found in tourniquets used for routine venipuncture, of which $25 \%$ of species found resulted to be multi-antibiotic resistant. In this regard the single-use disposable tourniquet seems to be a valuable alternative, as such kind of device shows the same comfort and usability as the traditional device $(32,33)$.

\section{Dealing with distress, pain and fear of needles}

Although minimal, venipuncture is an invasive procedure. Thus, piercing skin can cause distress, pain and even extreme reactions especially in children, mentally ill patient, and sometimes also in adults. The reduced compliance to venipuncture is a major issue for a phlebotomist, and demands a discussion about its management.

The pain or intra-procedural discomfort is a major factor in phlebotomy compliance, and depends on the mechanical force that the needle exerts on the skin to penetrate it, given the vein's wall has no nociceptive innervations. The reduction of the needle diameter, the thickness of the shaft's wall and the sharpness of the tip's profile have been shown to effectively improve the penetration (34). This in turn reduces the painful sensation to a 
small pinch (35-37). However, the thickness and consistency of skin layers, and thus the resistance opposed to needle penetration, determine the painful sensation as well (37). It should be noticed that the studies on needle penetration involve large $G$ needles used for subcutaneous insulin injection, which usually traumatize a very small surface. In these studies a gross difference of 0.07 $\mathrm{mm}^{2}$, corresponding to that between a $27 \mathrm{G}$ and $30 \mathrm{G}$, was enough to sensibly reduce the occurrence of pain during the skin puncture $(35,36)$. Therefore, due to the gross difference of $0.2 \mathrm{~mm}^{2}$ in their respective cross-section area, the $23 \mathrm{G}$ needle, which pierces an area of about $0.32 \mathrm{~mm}^{2}$, can be regarded as naturally more comfortable and less painful than the "larger" $21 \mathrm{G}$. Nonetheless the reduced inner diameter of smaller $G$ needles limits the blood flow, and slows the withdrawal of blood. This increases discomfort and distress, and thus the risk of autonomous reactions $(38,39)$. Thereby a $23 \mathrm{G}$ needle should be chosen to sample a small quantity of blood, or at least be used in a limited number of selected cases where a less traumatic penetration of the vein is required. Particularly the latter condition should correspond to that of small, fragile and easily collapsing vessels of elder patients, infants or subjects with a significant vasospasm, or for accessioning veins of certain body districts like the dorsal side of the hand.

Local anaesthetics, like lidocaine or prilocaine, have been successfully introduced to relieve the intra-procedural pain in children and in adults (4042). The topical application produces anaesthesia in more than 15 minutes, requires an appropriate application and can cause side effects like vasoconstriction, and erythema (43). However, the intra-dermal infiltrated needle-free lidocaine powder has been shown to have a quick onset time (less than 5 minutes), to be cost-effective, broadly applicable and well tolerated by patients $(41,44-$ 46). Alternatively, mechanical or thermal (hot or cold) stimulation of venipuncture neighbouring site can be used to relieve pain both in adults and children (47). Such approach relies on the gate control theory of pain, according to which the transmission of peripheral nociception can be reduced by a "competing" concomitant mechanic stimulus incoming from the same somatic district (Figure 2) $(48,49)$. In this regard, a device using high frequency vibrations and refrigeration has been devised for the use in children $(50,51)$. Particularly, it is a small $(8 \times 5 \times 2.5 \mathrm{~cm})$ bee-shaped plastic casing containing a battery-powered vibrator and a cold icepack, which has to be applied $5 \mathrm{~cm}$ above the venipuncture site and held in place throughout the entire procedure. Such a device has been shown to be well tolerated, significantly reducing the pain in 4 to 18 years old children, as well as considerably increasing the opportunity of a successful procedure (odds ratio 3.05, 95\% confidence interval 1.03 - 9.02) (51). Noteworthy, it has been shown to increase the compliance to venipuncture also in children with cognitive impairment (52). The use of this device demands a strict adherence to manufacturer instructions, or otherwise some haematological and biochemical parameters may result biased (53-55). In fact, the vibrating/refrigerating device is held in place by means of an elastic strap which acts as a tourniquet, and which can produce the same effects on the sample quality done with a regular tourniquet if fasted too tight or for too long.

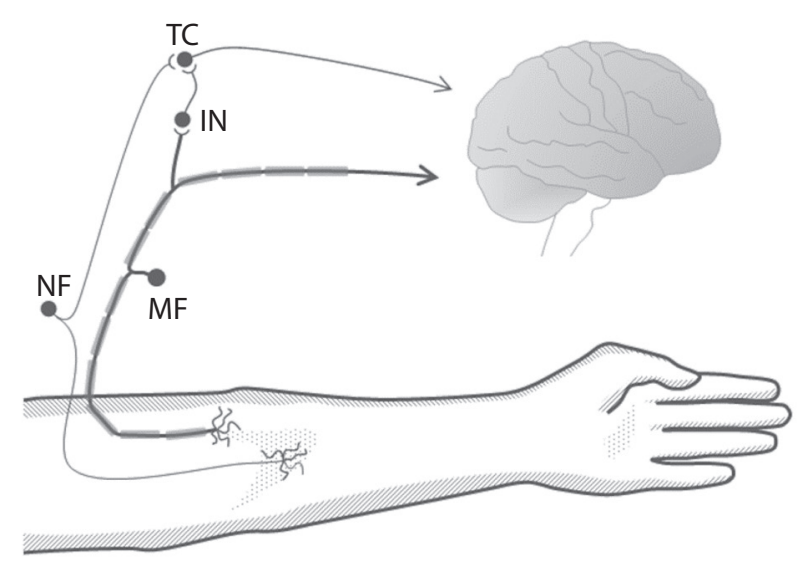

Figure 2. Schematic representation of the neuronal circuit involved in the gate control theory of pain; a nociceptive fibber (NF) transmits a signal incoming from a certain body area, to the central nervous system through a target cell (TC) located in the spinal cord; a fibber of a mechanoreceptor (MF) located in the same area transmits its signalling to either an inhibitory inter-neuron (IN) and to the central nervous system; the IN stimulated by the MF inhibits the TC to transmit the nociceptive signalling to the brain, thus attenuating the painful perception. 
None of such remedies has an effect over the socalled "pre-procedural" or anticipatory pain, which is a psychosomatic reaction that onsets for the fear of being hurt, to lose blood or to faint. As a consequence, the patient experiences anxiety and thus a reduced compliance to venipuncture. Age seems to be a main determinant in this context, with younger individuals showing higher self-related and phlebotomist-related anxiety (56). The adults can show an anxious behaviour with respect to phlebotomy, and in about $2 \%$ of the cases a clear phobia toward needles (defined as trypanophobia) can be recognized. Trypanophobia, as well as the more general blood-injury-injection phobia, can cause an autonomic reaction which accompanies the exposure to needles. It can produce in almost $5 \%$ of cases the so-called vasovagal reaction (VVR), in which the heart rate and blood pressure increase resembling a "fight-or-flight" response, and then suddenly drops precipitating into fainting (vasovagal syncope) $(56,57)$. The VVR is a harmless affection, which can lead to injuries due to the loss of control over body position, but which very rarely causes more severe consequences like death $(56,58)$. Besides the blood-injury-injection phobia, the other risk factors for VVR are small body size, low estimated blood volume, poor sleep $(<6$ hours), as well as the female gender and the Caucasian race (39). Moreover, the perceived or the believed blood loss can trigger the autonomous decompensation which is typical of VVR (59). Notably, a psychosomatic component, in which motivational an anticipatory cortical process toward the cause of the expected pain alters the nociceptive perception, can be recognized for the "intraprocedural" pain as well. This phenomenon can enhance the discrimination of the painful stimulus and in turn can magnify its intensity $(60,61)$.

Particular behavioural techniques can be applied against VVR. In this regard, the applied tension technique is a strategy which involves the body muscles tensing in order to raise the blood pressure and contrast the fainting $(62,63)$. Although it can be done by simply crossing and tightening the legs, the efficacy of such procedure relies on a fully cooperative patient. In case of children the so called "cough-trick" should be used instead (64). In this kind of approach, the child is asked to moderately cough one time just before the needle insertion ("warm-up cough") and then again at the skin piercing. Alternatively, the simpler distraction which can be obtained by playing with toys, viewing cartoons or listening to music can also be used, in order to successfully contrast the enhancement of the intra-procedural pain perception (65-68). Noteworthy, the same effect on the patient's compliance can be obtained by means of local anaesthetics, that reduce the physical perception of pain and can help in overcoming the needle issue, especially if they are delivered by a needle-free system $(46,69)$.

Lastly, a post-procedural pain can be found as a consequence of traumatic venipuncture. The main reasons are the formation of a large hematoma, a pseudo or true aneurisms due to the accidental puncture of the brachial artery, or the onset of a superficial phlebitis (70). In all those circumstances, the onset of pain is delayed respect to phlebotomy, and in some cases it can require a vascular surgery intervention $(71,72)$. However, such complications are very rare in routine venipuncture $(<$ $3 \%$ ), except for the formation of small harmless ecchymosis which occur in $15 \%$ of phlebotomies, and have a diameter of $<20 \mathrm{~mm}$ in $90 \%$ of the cases $(70,73)$.

As a personal remark, experience suggests that in those subjects that do not show any particular anticipatory sign, a reduced compliance to venipuncture can still occur. A typical condition is in case of a missed first attempt which requires a "searching" by needle probing of the bloodstream. Probably, the sight of the needle moved by the operator under the skin, or the longer than expected procedure may trigger an autonomic decompensation.

\section{Human anatomy and the approach to the veins}

A proverb of the ancient Romans, famous for having won most of the battles they fought, says that "amat victoria curam" which translates into "victory lies in a careful preparation". The care taken to recognize the most appropriate site to insert the needle is a key to determine the successful outcome 
of the procedure and reduces the risk of injuries. Therefore, the knowledge of anatomy, alongside with tools used to enhance their visualization, is mandatory and deserves an appropriate discussion, with the awareness that the goal is a suitable rather than a quick phlebotomy.

The main site to draw blood is represented by the cubital fossa of the forearm, which has the shape of an isosceles triangle with the biceps forming the base, and the lateral and medial groups of the antebrachial muscles forming the sides respectively (74). Although in the large part of individuals the running pattern of superficial veins appears well evident in this region, the path and distribution can be irregular and may require a careful inspection before attempting the needle insertion. The main veins in this area are represented by the cephalic (CV), the basilic (BV), the median cubital (MCV), the median antebrachial (MABV), and their various tributaries and anastomosis. Their distribution and connections can be classified into four types (I to IV), according to the dominance of CV or BV with respect to the calibre of the vessel (Figure 3) (75).

Notably, it is important to know the spatial relationship between the path of veins and cutaneous nerves that can be accidentally pinched during needle insertion, causing intense pain and nerve damage (76). For instance, the lateral cutaneous nerve of the forearm usually descends deeply along the CV while the medial cutaneous nerve of the forearm descends superficially along the BV (Figure 4) (77). The most common nerve injury related to venipuncture involves the lateral antebrachial cutaneous nerve (LACN), which can lead to the so-called "causalgia" or complex regional pain syndrome (CRPS) (78-80). The CRPS can range from a mild and temporary harm, which resolves within few months, up to a severe and permanent damage with chronic pain and the need of complex therapies (81). However this is a very rare consequence occurring in about $1: 25,000$ individuals undergoing blood donation (78). Noteworthy, the CRPS may be favoured by peculiar anatomical relationships between nerves and veins, as well as by the needle probing in case of a missed attempt (5). However some authors have reported that the use of winged needles may contribute to lower the risk of nerve injury at the upper limb site (82).

Due to congenital causes, extreme leanness or in children, the brachial artery can be found to run superficially, passing closely under the ulnar side of both MCV and BV (Figure 4) (83). In this case an excessive penetration into the vein can cause the needle to pass the vein from side to side, reaching the artery underneath. Although this happens in less than $0.01 \%$ of blood donors, it can cause sudden large hematoma with serious bleeding for the
A

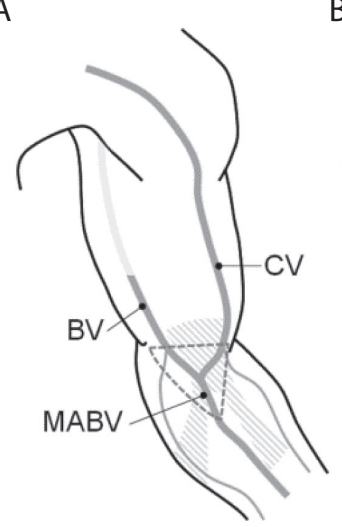

B

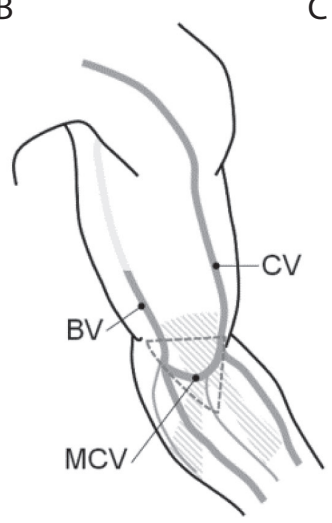

C

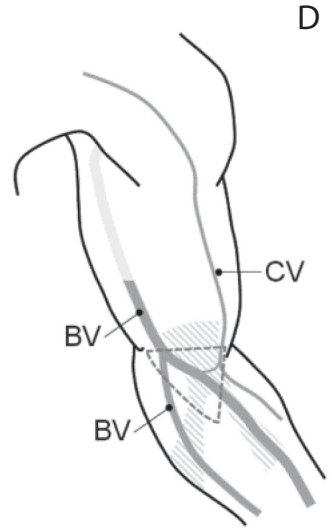

$D$

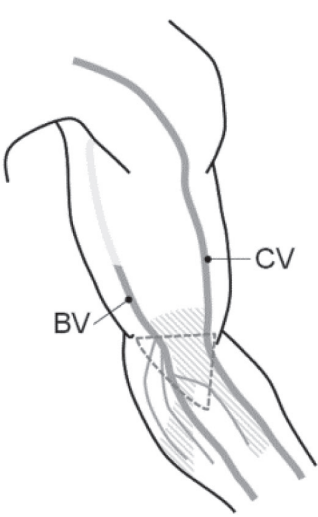

FIGURE 3. The superficial veins of the upper limb present a certain inter-individual variability in their running pattern and caliber; $A$ ) in type I, cephalic vein (CV) and basilic vein (BV) merge into the median antebrachial vein (MABV) of the forearm; B) in type II, the median cubital vein (MCV) forms an anastomose between CV and BV; C) in type III, CV is threadlike and BV splits in two branches of the forearm; D) in type IV, CV and BV run in parallel with no evident superficial anastomoses; the dashed triangle delimits the cubital fossa area. 


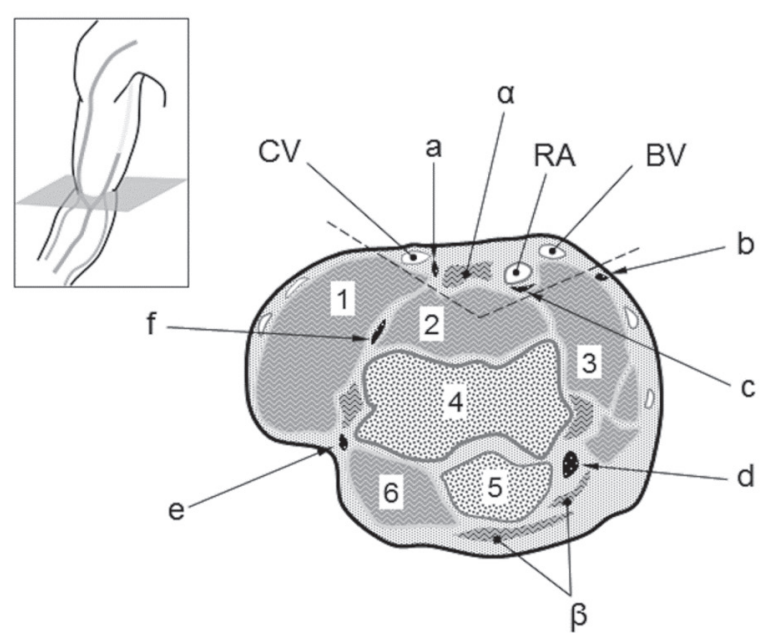

Figure 4. Topographic anatomy of the cubital fossa (cross-section at the elbow); vessels: (V) cephalic vein; RA) radial artery; BV) basilic vein; tendons: a) biceps brachii tendon; $\beta$ ) triceps brachii tendon); nerves: a) lateral antebrachial cutaneous nerve; b) medial antebrachial cutaneous nerve; c) median nerve; d) ulnar nerve; e) posterior lateral antebrachial nerve; f) radial nerve; muscles and bones: 1) brachioradialis; 2) brachialis; 3) pronator tenes; 4) trochlea (humerus); 5) olecranon (ulna); 6) anconeus.

high arterial pressure, or afterwards lead to a false or true aneurism of the artery $(71,72)$.

Inspection and especially palpation represent the basic approach to identify the site for venipuncture (Figure 5) (74). Palpation allows phlebotomist to recognize the vessel elasticity, depth and consistency of the surrounding tissues. Superficial veins can be poorly evident to sight and palpation in some coloured or obese people, so the tourniquet must be applied several inches above the site of venipuncture in order to enhance their path by inducing venous stasis. To achieve satisfactory result, a moderate pressure $(60 \mathrm{~mm} \mathrm{Hg})$ for a less than a minute is enough to suitably dilate the vein, avoiding the risk of inducing excessive venous stasis that can alter haematological and biochemical parameters. In terms of width of the venous vessel this condition corresponds to the achievement of the maximal venous cross-section area (VCSA), as it is shown by the ultrasonography imaging (84). Interestingly, an alternative to tourniquet application can be "stimulating" the vein by tapping the vessel, although its effect may be quite small on average producing just a $4 \%$ increase (85).

Sometimes, neither tourniquet nor tapping is effective. In all such cases, a technological help is provided by the trans-illuminating devices, which use the cold near infrared light-emitting diodes to light erythrocytes flowing inside the vessels (75). With such devices, the path of the vein appears as a colourless pattern drawn on a bright surface, as the infrared light which is absorbed by the erythrocytes is instead reflect by the neighboring tissues. In certain trans-illuminating devices the infrared image is not directly shown, but rather it is read by the device and then projected onto the skin surface to produce a guiding pattern for the operator (86). Such devices have been shown to improve the venipuncture procedure without affecting haematological parameters $(87,88)$. However, they do not produce any effect over the VCSA, so that small deep veins remain still hard to pierce although well visible.

Actually, there are alternative sites for venipuncture (89). They are mainly represented by the dorsal surface of the hand, where veins lay superficially because of the poor connective tissue and muscles. It must be noticed that this site has also the greater pain tolerance threshold among the upper limb sites, thus resulting in the lowest perceived pain intensity (90). Therefore, it may be eligible in those subjects with deep or small veins or with a particular issue of painful reactions. However, veins at this site have a greater mobility due to the poor surrounding connective tissue, and thus they

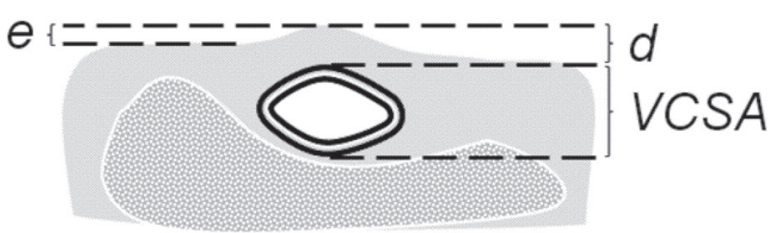

Figure 5. A superficial vein can be characterized according to its elevation (e) above the neighbouring skin surface, its depth (d) with respect to the thickness of the surrounding tissues, and its cross-section area (VCSA) with respect to its calibre (adapted from reference 84). 
more easily "roll" under the needle's tip or collapse, causing a missed attempt or a rupture of the vessel.

We would like to mention that a guidance on the good practice in phlebotomy (correct patient positioning, how to wear gloves, labelling samples, disposing used devices, etc.) can be found in the World Health Organization (WHO) issue on blood draw, as well as in the Clinical and Laboratory Standards Institute (CLSI) H3-A6 issue $(91,92)$. Noteworthy, also some national societies have issued their own guidelines and recommendations, like the Croatian Society of Medical Biochemistry and the Italian Society of Clinical Biochemistry/Italian Society of Laboratory Medicine $(93,94)$.

\section{The issue of preanalytics: what makes the difference after the blood has been drawn}

Collecting blood is the primary objective of venipuncture. Therefore the quality of the specimen, which rules the laboratory preanalytics, is crucial to ensure patient safety $(95,96)$. Indeed, the burden of preanalytical issues is well known to laboratorians, but sometimes it is underestimated by the phlebotomists which are rather focused on the immediate patient management. There are three major preanalytical issues arising from an incorrect blood draw procedure: haemoconcentration, spurious hyperkalemia and spurious haemolysis (97).

The tourniquet application causes the inner pressure of the vein to increase artificially. If prolonged or excessive, this constriction raises the hydrostatic pressure within the vessel, forcing the water to pass into the outer connective tissue. Thereafter, the collected sample can show haemoconcentration, an activated pro-coagulant response, as well as an altered platelets function (98-100). The prolonged venous stasis, which also favours tissue hypoxia, produces a change in $\mathrm{pH}$ which locally affects the electrolytes balance, especially potassium (101).

Since potassium is mainly intracellular, a false elevation in its blood level can be easily achieved through various processes. For instance, a strenuous or prolonged fist clenching or pumping leads to the increase of extracellular potassium due to the depolarization of the skeletal muscle cells (102). Nonetheless, mechanical stress on cells can similarly induce an increase of blood potassium through a membrane leakage. In this regard there are two major mechanical causes related to phlebotomy procedure: the shear stress on red blood cells flowing through a small bore needle which causes haemolysis and the needle probing of the bloodstream which damages the tissue neighbouring the venipuncture site (103-105). Under a clinical and laboratory standpoint, the condition in which a patient is found to have hyperkalemia with no other biochemical signs or relevant causes in the medical history is said spurious or pseudohyperkalemia (PHK) (106-108).

A remarkable cause of $\mathrm{PHK}$ associated with the phlebotomy procedure is the sample cross-contamination due to tube additives. As the standard haemochromocytometric analysis is carried out on anticoagulated blood sample, the sampling tubes with di- or tri-potassium salt of the ethylenediaminetetraacetic acid ( $\mathrm{K}_{2}$-EDTA and $\mathrm{K}_{3}$-EDTA) are routinely used. In this regard, it is noteworthy to address two distinct ways through which a sample can be contaminated by EDTA. If a syringe is used for drawing blood, it can happen when the blood is dispended in the tube containing the anticoagulant. In this case, the syringe's needle is thought to carry the contamination after it has accidentally touched the inner side of the tube coated with the anticoagulant. Instead, if an evacuated tubes system is used, the contamination can be due to the anticoagulated blood which stains the inner needle that perforates the tube stop. In this regard, the order in which the tubes containing different additives are drawn is relevant to prevent contamination. According to the correct order of drawing, an EDTA-containing tube should always be collected after a serum tube or a citrate-anticoagulated whole blood tube (91). Noteworthy, some authors have shown that with both Sarstedt's and evacuated tubes the recommendation of a precise tube order does not affect the blood testing $(109,110)$. However, it should be noted that draw- 
ing an EDTA tube after all the others physically prevents any possible contamination, regardless of the way the system is used as already mentioned in this paper. With respect to PHK it should be finally remarked that tube mixing, necessary to achieve the proper preservation of the collected blood, should be performed only after the tube has been removed from the holder (111).

Whenever an EDTA contamination happens, an abnormal reduction of serum calcium can be shown in the factitious electrolytes imbalance (112). Such a condition, which is defined pseudohypocalcemia $(\mathrm{PHC})$, is due to the strong chelating action EDTA exerts on divalent cations and ferric iron $\left(\mathrm{Fe}^{3+}\right)$. Noteworthy, the strong chelation of calcium can also interfere with coagulation testing, significantly biasing both prothrombin time (PT) and activated partial thromboplastin time (APTT) (113). Therefore, the advice to draw EDTA tubes at the end should be followed whenever any other weaker anti-coagulant is used to collect blood, as in case of lithium-heparin $(114,115)$.

Spurious haemolysis $(\mathrm{SH})$ is another common condition associated with venipuncture, and the most frequent cause of sample unsuitability $(116,117)$. The needle bore size along with the withdrawal force is the main factors of $\mathrm{SH}$, since them both induce a mechanical stress which causes the rupture of the cell membrane. In this regard, the needle bore size, and in turn the gauge, may be regarded as a reliable predictor of haemolysis, with $21 \mathrm{G}$ needles showing half the risk of producing an unsuitable sample respect to $23 \mathrm{G}$ (118). However, it should be noticed that the effectiveness of larger bore needles could be mitigated by the choice of the venipuncture site, and that such a lower estimated risk of haemolysis would be reliable only when the phlebotomy is performed on large veins of the antecubital fossa (119). Moreover, a $23 \mathrm{G}$ needle could be as safe as a $21 \mathrm{G}$ if handled correctly, whereas smaller bore size than $23 \mathrm{G}$ needle should be avoided or used in very rare and extreme circumstances (104). Actually, SH can affect several laboratory tests as the red blood cells contain analytes which are routinely tested in serum, like lactate dehydrogenase, aspartate aminotransferase and potassium $(116,120,121)$. Furthermore,
$\mathrm{SH}$ can cause the release of haemoglobin, whose iron-containing heme group can produce a spectrophotometric interference or, in turn, can react with some of the assay reagents. It is noteworthy to mention that swabbing the venipuncture site with alcohol-containing solutions does not cause any significant haemolysis (122). Haemolysis can be readily detected by visual inspection after sample centrifugation, and directly quantified through a spectrophotometric reading even at low concentration. However, for whole blood samples, haemolysis can be neither observed nor directly measured. Nonetheless, in recent times some authors have proposed an indirect assessment of haemolysis in whole blood samples using the automated cell blood count parameters to compute suitable and reliable indexes $(123,124)$.

Although not strictly related with the procedure of phlebotomy, there are some other issues which deserve a discussion, as they are among the most frequent causes of pre-analytical errors $(125,126)$. The misidentification of the patient as well as the incorrect labelling of the tubes were found to be a critical step in the quality of phlebotomy with respect to the burden of preanalytical errors (127). In this regard, the use of bar coding test tubes, along with the adoption of educational programs which helped to increase the compliance of the operators to the best practice guidelines, resulted successful in lowering the rate of unsuitable samples (128). During venipuncture, the choice of the appropriate tube to use with respect to the additive contained was another relevant factor found to significantly affect the quality of collected samples. Although the colour-code scheme was devised to help the operator in recognizing the additive within the tube, the broad heterogeneity in the scheme adopted by the various manufacturers and the lack of standardization resulted in a serious issue (11). Lastly, we would like to mention body positioning, which is a fundamental but often overlooked factor in laboratory preanalytics. Very recently it has been shown that changing the position from sitting to lying (and vice versa) causes a significant bias in several laboratory values, due to the gravitational adaptation which changes the hydrostatic pressure along the various body 
districts $(129,130)$. Noteworthy, the effect that the shift in plasma volume has on hematocrit is regarded as postural pseudoanemia for the consequence it has on haematological testing (131). Although there can be several ways through which phlebotomy can affect the laboratory preanalytics, not all of them produce a significant bias as it can be seen in Table 2 .

Following our reasoning on preanalytics issues, we would like to point out that any deviation from the correct blood drawn procedure should be always reported to the laboratory. Therefore, the phlebotomist should record such events like a poor patient preparation, the failure to rest or fast before blood collection, a body position different from sitting, the presence of a venous line in a neighbouring vascular district, a difficult vascular access, etcetera (127).

\section{Conclusion: crossing the bridge}

Phlebotomy might be erroneously considered a very simple and brief task to undertake. In this respect, a large multicenter study, which reported an average completion time of 6 minutes in about $50 \%$ of procedures, also showed that in $10 \%$ of cases the blood draw required at least 21 minutes or even a hour to be accomplished, with a third of the patients experiencing more distress or pain than expected (73).

It is thought that to achieve a good skill, corresponding to a rate of successful venipunctures close to $99 \%$ at first attempt, about one year of practice is necessary (132). However, the phlebotomist's success is not only in its numbers. The occurrence of VVR, which is one of the mostly feared complications follows a negative trend decreasing to a minimum in about one year (132). Interestingly, it is not possible to say whether such a coincidence between length of training and fall in the rate of VVR may come from the actual experience gained by the operator in promptly accessing suitable veins, or rather be due to the psychological effect exerted on patients by an "experiencedlooking" phlebotomist.

Through the years technology has provided some useful devices to aid the phlebotomists in their craft, increasing the quality of collected specimens

TABLE 2. Preanalytical bias of routine venipuncture.

\begin{tabular}{|c|c|c|c|c|c|}
\hline \multirow{2}{*}{$\begin{array}{c}\text { Venipuncture } \\
\text { factor } \\
\text { Lab } \\
\text { parameter }\end{array}$} & \multirow{2}{*}{$\begin{array}{c}\text { Needle } \\
\text { gauge } \\
23 \text { G vs. } \\
21 \text { G }\end{array}$} & \multirow{2}{*}{$\begin{array}{c}\text { Needle } \\
\text { type } \\
\text { Winged } \\
\text { vs. regular }\end{array}$} & \multicolumn{2}{|c|}{ Toruniquet application } & \multirow{2}{*}{$\begin{array}{l}\text { Body positioning } \\
\text { Sitting vs. lying }\end{array}$} \\
\hline & & & 1 minute & 3 minute & \\
\hline $\begin{array}{l}\text { Clinical } \\
\text { chemistry }\end{array}$ & negligible & negligible & $\begin{array}{l}\text { Albumin }(+1.58 \% ; \pm 1.3 \%) \\
\text { Calcium }(+1.6 \% ; \pm 0.8 \%) \\
\text { Chloride }(-0.5 \% ; \pm 0.5 \%) \\
\text { Potassium }(-2.8 \% ; \pm 1.8 \%)\end{array}$ & $\begin{array}{c}\text { ALT }(+15.7 \% ; \pm 12.0 \%) \\
\text { Albumin }(+8.6 \% ; \pm 1.3 \%) \\
\text { Calcium }(+3.6 \% ; \pm 0.8 \%) \\
\text { Chloride }(-1.1 \% ; \pm 0.5 \%) \\
\text { Cholesterol }(+9.1 \% ; \pm 4.0 \%) \\
\text { Glucose }(-3.7 \% ; \pm 2.2 \%) \\
\text { Iron }(+8.8 \% ; \pm 8.8 \%) \\
\text { Potassium }(-4.8 \% ; \pm 1.8 \%)\end{array}$ & $\begin{array}{l}\text { Albumin }(+2.0 \% ; \pm 1.4 \%) \\
\text { Protein }(+2.9 \% ; \pm 1.4 \%)\end{array}$ \\
\hline $\begin{array}{c}\text { Platelets and } \\
\text { coagulation }\end{array}$ & negligible & negligible & negligible & $\begin{array}{c}\text { PT/INR }(-3.1 \% ; \pm 2.0 \%) \\
\text { Fibrinogen }(+10.1 \% ; \pm 4.8 \%)\end{array}$ & n.a. \\
\hline Haematology & n.a. & negligible & $\begin{array}{c}\text { WBC }(-6.7 \% ; \pm 5.6 \%) \\
\text { RBC }(+3.6 \% ; \pm 1.7 \%) \\
\text { Haemoglobin }(+3.0 \% ; \pm 1.8 \%) \\
\text { Haematocrit }(+3.7 \% ; \pm 1.7 \%) \\
\text { Lymphocytes }(-7.9 \% ; \pm 7.4 \%) \\
\text { Monocytes }(-14.4 \% ; \pm 13.2 \%)\end{array}$ & $\begin{array}{c}\text { WBC }(-10.1 \% ; \pm 5.6 \%) \\
\text { RBC }(+7.4 \% ; \pm 1.7 \%) \\
\text { Haemoglobin }(+6.2 ; \pm 1.8 \%) \\
\text { Haematocrit }(+7.3 \% ; \pm 1.7 \%) \\
\text { Lymphocytes }(-10.7 \% ; \pm 7.4 \%) \\
\text { Monocytes }(-22.0 \% ; \pm 13.2 \%)\end{array}$ & $\begin{array}{l}\text { Haemoglobin }(+2.3 \% ; \pm 1.8 \%) \\
\text { Haematocrit }(+1.7 \% ; \pm 1.7 \%)\end{array}$ \\
\hline
\end{tabular}

Data in brackets are the actual and desirable bias respectively; "n.a." indicates factors for which bias was not measured regardless to a significant effect may exist. 
and the safety of the patients. Moreover, the evidence based medicine paradigm has codified the tricks of the trade into procedures and rules, giving precise references and guidance. However, there is no mathematical formula that can tell which is the right vein, the right needle, the right angle and the right force that will give the perfect

\section{References}

1. Parapia LA. History of bloodletting by phlebotomy. Br J Haematol 2008;143:490-5. http://dx.doi.org/10.1111/j.13652141.2008.07361.x.

2. Forsman RW. Why is the laboratory an afterthought for managed care organizations? Clin Chem 1996;42:813-6.

3. Kravetz RE. Hypodermic syringe. Am J Gastroenterol 2005;10:2614. http://dx.doi.org/10.1111/j.1572-0241.2005. 00397.x.

4. Ernst DJ, Ernst C. Phlebotomy tools of the trade. Home healthc nurse 2002;20:151-3. http://dx.doi. org/10.1097/00004045-200203000-00005.

5. Fujii C. Clarification of the characteristics of needle-tip movement during vacuum venipuncture to improve safety. Vasc Health Risk Manag 2013;9:381-90. http://dx.doi. org/10.2147/NHRM.S47490.

6. Lippi G, Salvagno GL, Brocco G, Guidi GC. Preanalytical variability in laboratory testing:influence of the blood drawing technique. Clin Chem Lab Med 2005;43:319-25. http:// dx.doi.org/10.1515/CCLM.2005.055.

7. Fujii C. Vacuum-venipuncture skills:time required and importance of tube order. Vasc Health Risk Manag 2013;9:45764. http://dx.doi.org/10.2147/VHRM.S49702.

8. Gershon RR, Pearson JM, Sherman MF, Samar SM, Canton $A N$, Stone PW. The prevalence and risk factors for percutaneous injuries in registered nurses in the home health care sector. Am J Infect Control 2009;37:525-33. http://dx.doi. org/10.1016/j.ajic.2008.10.022.

9. European Council Directive 2010/32/EU. Available at: http:// europeanbiosafetynetwork.eu/OJEU.pdf. Accessed: September 15, 2015

10. Bush V, Cohen R. The Evolution of Evacuated Blood Collection Tubes. Lab Medicine 2003;34:304-10. http://dx.doi. org/10.1309/JCQE33NBYGEOFFQR.

11. Simundic AM, Cornes MP, Grankvist K, Lippi G, Nybo M, Ceriotti F, et al. Colour coding for blood collection tube closures a call for harmonisation. Clin Chem Lab Med 2015;53:371-6. http://dx.doi.org/10.1515/cclm-2014-0927.

12. McGuff J, Popovsky MA. Needlestick injuries in blood collection staff. A retrospective analysis. Transfusion 1989;29:693-5. http://dx.doi.org/10.1046/j.15372995.1989.29890020442.x.

13. Holton J, Prince M. Blood contamination during venepuncture and laboratory manipulations of specimen tubes. $J$ Hosp Infect 1986;8:178-83. http://dx.doi.org/10.1016/01956701(86)90044-7. blood draw. The only certainty is that all the efforts made to grant the safety of the customers and the quality of the service allows phlebotomy to bridge the gap between patient and laboratory.

\section{Potential conflict of interest}

None declared.

14. On track for success for more than 50 years. Available at: https://www.sarstedt.com/en/the-company/about-us/history/. Accessed: September 15, 2015

15. Lippi G, Bonelli P, Bonfanti L, Cervellin G. The use of S-Monovette is effective to reduce the burden of hemolysis in a large urban emergency department. Biochem Med (Zagreb) 2015;25:69-72. http://dx.doi.org/10.11613/BM.2015.008.

16. Lippi G, Avanzini P, Musa R, Sandei F, Aloe R, Cervellin G. Evaluation of sample hemolysis in blood collected by $S$ Monovette using vacuum or aspiration mode. Biochem Med (Zagreb) 2013;23:64-9. http://dx.doi.org/10.11613/ BM.2013.008.

17. Goldman M, Roy G, Frechette N, Decary F, Massicotte L, Delage G. Evaluation of donor skin disinfection methods. Transfusion 1997;37:309-12. http://dx.doi.org/10.1046/j.15372995.1997.37397240214.x.

18. Ramirez-Arcos S, Goldman M. Skin disinfection methods:prospective evaluation and postimplementation results. Transfusion 2010;50:59-64. http://dx.doi. org/10.1111/j.1537-2995.2009.02434.x.

19. Evans CA, Mattern KL. The bacterial flora of the antecubital fossa:the efficacy of alcohol disinfection of this site, the palm and the forehead. J Invest Dermatol 1980;75:140-3. http://dx.doi.org/10.1111/1523-1747.ep12521658.

20. Muller FO, Hundt HK. Ethyl alcohol:contamination of blood specimens. S Afr Med J 1976;50:91.

21. Yigit O, Arslan S. Swabbing skin with alcohol could change the blood alcohol level significantly. J Emerg Med 2012;43:718-9. http://dx.doi.org/10.1016/j.jemermed.2011.07.025.

22. Caldeira D, David C, Sampaio C. Skin antiseptics in venous puncture-site disinfection for prevention of blood culture contamination:systematic review with meta-analysis. J Hosp Infect 2011;77:223-32. http://dx.doi.org/10.1016/j. jhin.2010.10.015.

23. Mclvor RA, Cosbey SH. Effect of using alcoholic and nonalcoholic skin cleansing swabs when sampling blood for alcohol estimation using gas chromatography. $\mathrm{Br} J$ Clin Pract 1990;44:235-6.

24. Tucker A, Trethewy C. Lack of effect on blood alcohol level of swabbing venepuncture sites with 70\% isopropyl alcohol. Emerg Med Australas 2010;22:9-12. http://dx.doi. org/10.1111/j.1742-6723.2009.01248.x. 
25. Malingre $M$, Ververs $T$, Bos $S$, van Kesteren $C$, van Rijn $H$. Alcohol swabs and venipuncture in a routine hospital setting:no effect on blood ethanol measurement. Ther Drug Monit 2005;27:403-4. http://dx.doi.org/10.1097/01. ftd.0000158868.74618.dd.

26. Pendlington RU, Whittle E, Robinson JA, Howes D. Fate of ethanol topically applied to skin. Food Chem Toxicol 2001;39:169-74. http://dx.doi.org/10.1016/S02786915(00)00120-4.

27. Brown CG. Comment on "Blood Alcohol Concentration Using Non-Alcohol- and Alcohol-Containing Skin Antiseptics". Ann Emerg Med 1983;12:593-5. http://dx.doi. org/10.1016/S0196-0644(83)80326-6.

28. Maiwald M, Chan ES. The forgotten role of alcohol:a systematic review and meta-analysis of the clinical efficacy and perceived role of chlorhexidine in skin antisepsis. PLOS One 2012;7:e44277. http://dx.doi.org/10.1371/journal. pone.0044277.

29. Calfee DP, Farr BM. Comparison of four antiseptic preparations for skin in the prevention of contamination of percutaneously drawn blood cultures:a randomized trial. J Clin Microbiol 2002;40:1660-5. http://dx.doi.org/10.1128/ JCM.40.5.1660-1665.2002.

30. Kiyoyama T, Tokuda Y, Shiiki S, Hachiman T, Shimasaki T, Endo K. Isopropyl alcohol compared with isopropyl alcohol plus povidone-iodine as skin preparation for prevention of blood culture contamination. J Clin Microbiol 2009;47:54-8. http://dx.doi.org/10.1128/JCM.01425-08.

31. Qamruddin A, Khanna N, Orr D. Peripheral blood culture contamination in adults and venepuncture technique:prospective cohort study. J Clin Pathol 2008;61: 509-13. http://dx.doi.org/10.1136/jcp.2007.047647.

32. Kerstein RL, Fellowes C. Novel fit for purpose single use tourniquet:best of both worlds. JMed Eng Technol 2009;33:47580. http://dx.doi.org/10.1080/03091900902952667.

33. Leitch A, McCormick I, Gunn I, Gillespie T. Reducing the potential for phlebotomy tourniquets to act as a reservoir for meticillin-resistant Staphylococcus aureus. J Hosp Infect 2006;63:428-31. http://dx.doi.org/10.1016/j.jhin.2006.03.006.

34. Gill HS, Prausnitz MR. Does needle size matter? J Diabetes Sci Technol 2007;1:725-9. http://dx.doi.org/10.1177/ 193229680700100517.

35. Arendt-Nielsen L, Egekvist H, Bjerring P. Pain following controlled cutaneous insertion of needles with different diameters. Somatosens Mot Res 2006;23:37-43. http://dx.doi. org/10.1080/08990220600700925.

36. Egekvist H, Bjerring P, Arendt-Nielsen L. Pain and mechanical injury of human skin following needle insertions. Eur J Pain 1999;3:41-9. http://dx.doi.org/10.1016/S10903801(99)90187-8.

37. Egekvist $H$, Bjerring $P$, Arendt Nielsen T. Regional variations in pain to controlled mechanical skin traumas from automatic needle insertions and relations to ultrasonography. Skin Res Technol 1999;5:247-54. http://dx.doi. org/10.1111/j.1600-0846.1999.tb00137.x.

38. Newman $B$, Siegfried B, Buchanan $L$. Are vasovagal reaction rates in blood donors related to the duration of the phlebotomy? Transfusion 2008;48:568-9. http://dx.doi. org/10.1111/j.1537-2995.2007.01638.x.
39. Newman BH. Management of young blood donors. Transfus Med Hemother 2014;41:284-95. http://dx.doi. org/10.1159/000364849.

40. Zempsky WT, Schmitz ML, Meyer JM. Safety and efficacy of needle-free powder lidocaine delivery system in adult patients undergoing venipuncture or peripheral venous cannulation:randomized, double-blind, placebo-controlled trial. Clin J Pain 2015; [Epub ahead of print]. http://dx.doi. org/10.1097/AJP.0000000000000257.

41. Zempsky WT, Bean-Lijewski J, Kauffman RE, Koh JL, Malviya SV, Rose JB, et al. Needle-free powder lidocaine delivery system provides rapid effective analgesia for venipuncture or cannulation pain in children:randomized, double-blind comparison of venipuncture and venous cannulation pain after fast-onset needle-free powder lidocaine or placebo treatment trial. Pediatrics 2008;121:979-87. http://dx.doi. org/10.1542/peds.2007-0814.

42. Patterson $P$, Hussa AA, Fedele KA, Vegh GL, Hackman CM. Comparison of 4 analgesic agents for venipuncture. AANA J 2000;68:43-51.

43. Brenner SM, Rupp V, Boucher J, Weaver K, Dusza SW, Bokovoy J. A randomized, controlled trial to evaluate topical anesthetic for 15 minutes before venipuncture in pediatrics. Am J Emerg Med 2013;31:20-5. http://dx.doi.org/10.1016/j. ajem.2012.05.003.

44. Schmitz ML, Zempsky WT, Meyer JM. Safety and efficacy of a needle-free powder lidocaine delivery system in pediatric patients undergoing venipuncture or peripheral venous cannulation:randomized bouble-blind COMFORT-004 trial. Clin Ther 2015;37:1761-72. http://dx.doi.org/10.1016/j. clinthera.2015.05.515.

45. Migdal M, Chudzynska-Pomianowska E, Vause E, Henry E, Lazar J. Rapid, needle-free delivery of lidocaine for reducing the pain of venipuncture among pediatric subjects. Pediatrics 2005;115:e393-8. http://dx.doi.org/10.1542/peds.2004-0656.

46. Patakfalvi L, Benohanian A. Needle-free anaesthesia, a promising option for the needle-phobic patient. Br J Dermatol 2014;170:1191-2. http://dx.doi.org/10.1111/bjd.12784.

47. Hogan ME, Smart S, Shah V, Taddio A. A systematic review of vapocoolants for reducing pain from venipuncture and venous cannulation in children and adults. J Emerg Med 2014;47:736-49. http://dx.doi.org/10.1016/j.jemermed.2014.06.028.

48. Braz J, Solorzano C, Wang X, Basbaum Al. Transmitting pain and itch messages:a contemporary view of the spinal cord circuits that generate gate control. Neuron 2014;82:522-36. http://dx.doi.org/10.1016/j.neuron.2014.01.018.

49. Mendell LM. Constructing and deconstructing the gate theory of pain. Pain 2014;155:210-6. http://dx.doi. org/10.1016/j.pain.2013.12.010.

50. Baxter AL, Leong T, Mathew B. External thermomechanical stimulation versus vapocoolant for adult venipuncture pain: pilot data on a novel device. Clin J Pain 2009;25:70510. http://dx.doi.org/10.1097/AJP.0b013e3181af1236.

51. Baxter AL, Cohen LL, McElvery HL, Lawson ML, von Baeyer $C L$. An integration of vibration and cold relieves venipuncture pain in a pediatric emergency department. Pediatr Emerg Care 2011;27:1151-6. http://dx.doi.org/10.1097/ PEC.0b013e318237ace4. 
52. Schreiber S, Cozzi G, Rutigliano R, Assandro P, Tubaro M, Cortellazzo Wiel $L$, et al. Analgesia by cooling vibration $d u-$ ring venipuncture in children with cognitive impairment. Acta Paediatr 2016;105:e12-6. http://dx.doi.org/10.1111/ apa. 13224.

53. Lima-Oliveira G, Lippi G, Salvagno GL, Montagnana $M$, Picheth G, Guidi GC. Quality impact on diagnostic blood specimen collection using a new device to relieve venipuncture pain. Indian J Clin Biochem 2013;28:235-41. http://dx.doi.org/10.1007/s12291-013-0319-y.

54. Lima-Oliveira G, Lippi G, Salvagno GL, Campelo MD, Tajra $K S$, dos Santos Gomes F, et al. A new device to relieve venipuncture pain can affect haematology test results. Blood transfus 2014;12:S6-S10.

55. Baxter AL, Lawson ML. Concerns with the methodology, analysis and discussion of the Buzzy $(R)$ and transillumination comparison article. Blood transfus 2014;12:S3-S5.

56. Deacon B, Abramowitz J. Fear of needles and vasovagal reactions among phlebotomy patients. J Anxiety Disord 2006;20:946-60. http://dx.doi.org/10.1016/j. janxdis.2006.01.004.

57. Ritz T, Meuret AE, Ayala ES. The psychophysiology of bloodinjection-injury phobia: looking beyond the diphasic response paradigm. Int J Psychophysiol 2010;78:50-67. http:// dx.doi.org/10.1016/j.ijpsycho.2010.05.007.

58. Newman BH, Graves S. A study of 178 consecutive vasovagal syncopal reactions from the perspective of safety. Transfusion 2001;41:1475-9. http://dx.doi.org/10.1046/j.15372995.2001.41121475.x.

59. Ditto B, Balegh S, Gilchrist PT, Holly CD. Relation between perceived blood loss and vasovagal symptoms in blood donors. Clin Auton Res 2012;22:113-6. http://dx.doi. org/10.1007/s10286-011-0147-1.

60. Babiloni C, Brancucci A, Capotosto P, Del Percio C, Romani GL, Arendt-Nielsen L, et al. Different modalities of painful somatosensory stimulations affect anticipatory cortical processes:a high-resolution EEG study. Brain Res Bull 2007;71:475-84. http://dx.doi.org/10.1016/j.brainresbull.2006.10.025.

61. Babiloni C, Brancucci A, Del Percio C, Capotosto P, ArendtNielsen L, Chen AC, et al. Anticipatory electroencephalography alpha rhythm predicts subjective perception of pain intensity. Pain 2006;7:709-17. http://dx.doi.org/10.1016/j. jpain.2006.03.005.

62. Holly CD, Torbit L, Ditto B. Applied tension and coping with blood donation:a randomized trial. Ann Behav Med 2012;43:173-80. http://dx.doi.org/10.1007/s12160-0119315-8.

63. Ditto B, France CR, Lavoie P, Roussos $M$, Adler PS. Reducing reactions to blood donation with applied muscle tension:a randomized controlled trial. Transfusion 2003;43:1269-75. http://dx.doi.org/10.1046/j.1537-2995.2003.00488.x.

64. Usichenko TI, Pavlovic D, Foellner S, Wendt M. Reducing venipuncture pain by a cough trick:a randomized crossover volunteer study. Anesth Analg 2004;98:343-5. http://dx.doi. org/10.1213/01.ANE.0000094983.16741.AF.
65. Babiloni C, Brancucci A, Arendt-Nielsen L, Babiloni F, Capotosto $P$, Carducci $F$, et al. Attentional processes and cognitive performance during expectancy of painful galvanic stimulations:a high-resolution EEG study. Behav Brain Res 2004; 152:137-47.

66. Del Percio C, Le Pera D, Arendt-Nielsen L, Babiloni C, Brancucci $A$, Chen $A C$, et al. Distraction affects frontal alpha rhythms related to expectancy of pain:an EEG study. Neuroimage 2006;31:1268-77. http://dx.doi.org/10.1016/j.neuroimage.2006.01.013.

67. MacLaren JE, Cohen LL. A comparison of distraction strategies for venipuncture distress in children. J Pediatr Psychol 2005;30:387-96. http://dx.doi.org/10.1093/jpepsy/jsi062

68. Bagnasco A, Pezzi E, Rosa F, Fornonil L, Sasso L. Distraction techniques in children during venipuncture:an Italian experience. J Prev Med Hyg 2012;53:44-8.

69. Szmuk P, Szmuk E, Ezri T. Use of needle-free injection systems to alleviate needle phobia and pain at injection. Expert Rev Pharmacoecon Outcomes Res 2005;5:467-77. http://dx.doi. org/10.1586/14737167.5.4.467

70. Galena HJ. Complications occurring from diagnostic venipuncture. J Fam Pract 1992;34:582-4.

71. Bhatti K, Ali S, Shamugan SK, Ward AS. True brachial artery aneurysm following blood donation: a case report of a rare complication. Eur J Vasc Endovasc Surg 2007;13:44-6.

72. Newman BH. Arterial puncture phlebotomy in whole-blood donors. Transfusion 2001;41:1390-2. http://dx.doi. org/10.1046/j.1537-2995.2001.41111390.x.

73. Howanitz PJ, Cembrowski GS, Bachner P. Laboratory phlebotomy. College of American Pathologists Q-Probe study of patient satisfaction and complications in 23,783 patients. Arch Pathol Lab Med 1991;115:867-72.

74. Ernst DJ, Ernst C. Phlebotomy tools of the trade: part 2: surveying the antecubital area. Home healthc nurse 2002;20:402-3. http://dx.doi.org/10.1097/00004045200206000-00021.

75. Lee H, Lee SH, Kim SJ, Choi WI, Lee JH, Choi IJ. Variations of the cubital superficial vein investigated by using the intravenous illuminator. Anat Cell Bio 2015;48:62-5. http:// dx.doi.org/10.5115/acb.2015.48.1.62

76. Berry $P R$, Wallis WE. Venepuncture nerve injuries. Lancet 1977;1:1236-7. http://dx.doi.org/10.1016/S01406736(77)92442-4.

77. Yamada K, Yamada K, Katsuda I, Hida T. Cubital fossa venipuncture sites based on anatomical variations and relationships of cutaneous veins and nerves. Clin Anat 2008;21:307-13. http://dx.doi.org/10.1002/ca.20622.

78. Rayegani SM, Azadi A. Lateral antebrachial cutaneous nerve injury induced by phlebotomy. J Brachial Plex Peripher Nerve Inj 2007;2:6.

79. Ramos JA. Venipuncture-related lateral antebrachial cutaneous nerve injury:what to know? Braz J Anesthesiol 2014;64:131-3. http://dx.doi.org/10.1016/j.bjane.2013.06.003.

80. Horowitz SH. Venipuncture-induced causalgia:anatomic relations of upper extremity superficial veins and nerves, and clinical considerations. Transfusion 2000;40:1036-40. http:// dx.doi.org/10.1046/j.1537-2995.2000.40091036.x. 
81. Elahi F, Reddy CG. Venipuncture-induced complex regional pain syndrome:a case report and review of the literature. $J$ Med Case Rep 2014;2014:613921.

82. Ohnishi H, Watanabe M, Watanabe T. Butterfly needles reduce the incidence of nerve injury during phlebotomy. Arch Pathol Lab Med 2012;136:352. http://dx.doi.org/10.5858/ arpa.2011-0431-LE.

83. Mikuni Y, Chiba S, Tonosaki Y. Topographical anatomy of superficial veins, cutaneous nerves, and arteries at venipuncture sites in the cubital fossa. Anat Sci Int 2013;88:4657. http://dx.doi.org/10.1007/s12565-012-0160-z.

84. Sasaki S, Murakami N, Matsumura Y, Ichimura M, Mori M. Relationship between tourniquet pressure and a cross-section area of superficial vein of forearm. Acta Med Okayama 2012;66:67-71.

85. Ichimura M, Sasaki S, Mori M, Ogino T. Tapping but not massage enhances vasodilation and improves venous palpation of cutaneous veins. Acta Med Okayama 2015;69:79-85.

86. Miyake RK, Zeman HD, Duarte FH, Kikuchi R, Ramacciotti E, Lovhoiden $G$, et al. Vein imaging: a new method of near infrared imaging, where a processed image is projected onto the skin for the enhancement of vein treatment. Dermatol Surg 2006;32:1031-8.

87. Lima-Oliveira G, Lippi G, Salvagno GL, Montagnana $M$, Scartezini M, Guidi GC, et al. Transillumination:a new tool to eliminate the impact of venous stasis during the procedure for the collection of diagnostic blood specimens for routine haematological testing. Int J Lab Hematol 2011;33:457-62.

88. Lima-Oliveira G, Lippi G, Salvagno GL, Montagnana $M$, Manguera $C L$, Sumita NM, et al. New ways to deal with known preanalytical issues:use of transilluminator instead of tourniquet for easing vein access and eliminating stasis on clinical biochemistry. Biochem Med (Zagreb) 2011;21:152-9. http://dx.doi.org/10.11613/BM.2011.024

89. Ernst DJ, Ernst C. Phlebotomy tools of the trade: part 3: Alternative sites for drawing blood. Home healthc nurse. 2003;21:156-8. http://dx.doi.org/10.1097/00004045200303000-00006.

90. Yoshida M, Shiiba S, Sago T, Nunomaki M, Harano N, Watanabe S. Comparison of pain tolerance thresholds of upper limb to identify the most appropriate venipuncture site. J Oral Maxillofac Surg 2015;73:850 e 1-5.

91. Clinical and Laboratory Standards Institute, Procedures for the Collection of Diagnostic Blood Specimens by Venipuncutre; Approved Standard - Sixth Edition. CLSI document H3-A5. Wayne, PA, USA, 2007.

92. World Health Organization (WHO) guidelines on drawing blood: best practices in phlebotomy: WHO Press; 2010. 125 p.

93. Lippi G, Caputo M, Banfi G, Buttarello M, Ceriotti F, Daves M, et al. Raccomandazioni per il prelievo di sangue venoso. Bioch Clin 2008;32:6569-77.

94. Nikolac N, Supak-Smolcic V, Simundic AM, Celap I, Croatian Society of Medical B, Laboratory M. Croatian Society of Medical Biochemistry and Laboratory Medicine: national recommendations for venous blood sampling. Biochem Med (Zagreb) 2013;23:242-54. http://dx.doi.org/10.11613/ BM.2013.031.
95. Plebani M. Errors in clinical laboratories or errors in la boratory medicine? Clin Chem Lab Med 2006;44:750-9. http://dx.doi.org/10.1515/CCLM.2006.123.

96. Lippi G, Guidi GC, Mattiuzzi C, Plebani M. Preanalytical variability:the dark side of the moon in laboratory testing. Clin Chem Lab Med 2006;44:358-65. http://dx.doi. org/10.1515/CCLM.2006.073.

97. Lippi G, Salvagno GL, Montagnana M, Franchini M, Guidi GC. Phlebotomy issues and quality improvement in results of laboratory testing. Clin Lab 2006;52:217-30.

98. Lippi G, Salvagno GL, Montagnana M, Franchini M, Guidi GC. Venous stasis and routine hematologic testing. Clin Lab Haematol 2006;28:332-7. http://dx.doi.org/10.1111/ j.1365-2257.2006.00818.x.

99. Lippi G, Salvagno GL, Montagnana M, Guidi GC. Shortterm venous stasis influences routine coagulation testing. Blood Coagul Fibrinolysis 2005;16:453-8. http://dx.doi. org/10.1097/01.mbc.0000178828.59866.03.

100. Lima-Oliveira G, Lippi G, Salvagno GL, Gaino S, Poli G, Gelati $M$, et al. Venous stasis and whole blood platelet aggregometry:a question of data reliability and patient safety. Blood Coagul Fibrinolysis 2015;26:665-8. http:// dx.doi.org/10.1097/MBC.0000000000000342.

101. Lippi G, Salvagno GL, Montagnana M, Brocco G, Guidi GC. Influence of short-term venous stasis on clinical chemistry testing. Clin Chem Lab Med 2005;43:869-75. http:// dx.doi.org/10.1515/CCLM.2005.146.

102. Seimiya $M$, Yoshida $T$, Sawabe $Y$, Sogawa K, Umemura $H$, Matsushita $K$, et al. Reducing the incidence of pseudohyperkalemia by avoiding making a fist during phlebotomy:a quality improvement report. Am J Kidney Dis 2010;56:686-92. http://dx.doi.org/10.1053/j. ajkd.2010.06.014.

103. Lippi G, Salvagno GL, Montagnana M, Poli G, Guidi GC. Influence of the needle bore size on platelet count and routine coagulation testing. Blood Coagul Fibrinolysis 2006;17:557-61. http://dx.doi.org/10.1097/01. mbc.0000245300.10387.ca.

104. Lippi G, Salvagno GL, Montagnana M, Brocco G, Cesare Guidi $G$. Influence of the needle bore size used for collecting venous blood samples on routine clinical chemistry testing. Clin Chem Lab Med 2006;44:1009-14. http:// dx.doi.org/10.1515/CCLM.2006.172.

105. Asirvatham JR, Moses V, Bjornson L. Errors in potassium measurement:a laboratory perspective for the clinician. North Am J Med Sci 2013;5:255-9. http://dx.doi. org/10.4103/1947-2714.110426.

106. Sevastos $N$, Theodossiades G, Archimandritis AJ. Pseudohyperkalemia in serum:a new insight into an old phenomenon. Clin Med Res 2008;6:30-2. http://dx.doi. org/10.3121/cmr.2008.739.

107. Stankovic AK, Smith S. Elevated serum potassium values:the role of preanalytic variables. Am J Clin Pathol 2004;121:S105-S12.

108. Cornes MP, Ford C, Gama R. Spurious hyperkalaemia due to EDTA contamination: common and not always easy to identify. Ann Clin Biochem 2008;45:601-3. http://dx.doi. org/10.1258/acb.2008.007241. 
109. Sulaiman RA, Cornes MP, Whitehead SJ, Othonos N, Ford C, Gama R. Effect of order of draw of blood samples during phlebotomy on routine biochemistry results. J Clin Pathol 2011;64:1019-20. http://dx.doi.org/10.1136/jclinpath-2011-200206.

110. Salvagno G, Lima-Oliveira G, Brocco G, Danese E, Guidi GC, Lippi G. The order of draw:myth or science? Clin Chem Lab Med 2013;51:2281-5. http://dx.doi.org/10.1515/cclm2013-0412.

111. Lima-Oliveira G, Lippi G, Salvagno GL, Brocco G, Gaino S, Dima F, et al. Processing of diagnostic blood specimens: is it really necessary to mix primary blood tubes after collection with evacuated tube system? Biopreserv Biobank 2014;12:53-9. http://dx.doi.org/10.1089/bio.2013.0043.

112. Naguib MT, Evans N. Combined false hyperkalemia and hypocalcemia due to specimen contamination during routine phlebotomy. South Med J 2002;95:1218-20. http://dx.doi.org/10.1097/00007611-200295100-00025.

113. Lima-Oliveira G, Salvagno GL, Danese E, Favaloro EJ, Guidi GC, Lippi G. Sodium citrate blood contamination by $K 2$ -ethylenediaminetetraacetic acid (EDTA):impact on routine coagulation testing. Int J Lab Hematol 2015;37:403-9. http://dx.doi.org/10.1111/ijlh.12301.

114. Lima-Oliveira G, Salvagno GL, Danese E, Brocco G, Guidi GC, Lippi G. Contamination of lithium heparin blood by K2-ethylenediaminetetraacetic acid (EDTA): an experimental evaluation. Biochem Med (Zagreb) 2014;24:35967. http://dx.doi.org/10.11613/BM.2014.038.

115. Lima-Oliveira G, Lippi G, Salvagno GL, Montagnana $M$, Picheth G, Guidi GC. Incorrect order of draw could be mitigate the patient safety:a phlebotomy management case report. Biochem Med (Zagreb) 2013;23:218-23. http:// dx.doi.org/10.11613/BM.2013.026.

116. Lippi G, Salvagno GL, Montagnana M, Brocco G, Guidi GC. Influence of hemolysis on routine clinical chemistry testing. Clin Chem Lab Med 2006;44:311-6. http://dx.doi. org/10.1515/CCLM.2006.054.

117. Lippi G, Blanckaert N, Bonini P, Green S, Kitchen S, Palicka $V$, et al. Haemolysis: an overview of the leading cause of unsuitable specimens in clinical laboratories. Clin Chem Lab Med 2008;46:764-72. http://dx.doi.org/10.1515/ CCLM.2008.170.

118. Wollowitz A, Bijur PE, Esses D, John Gallagher E. Use of butterfly needles to draw blood is independently associated with marked reduction in hemolysis compared to intravenous catheter. Acad Emerg Med 2013;20:1151-5. http://dx.doi.org/10.1111/acem.12245.

119. Heyer NJ, Derzon JH, Winges L, Shaw C, Mass D, Snyder $S R$, et al. Effectiveness of practices to reduce blood sample hemolysis in EDs:a laboratory medicine best practices systematic review and meta-analysis. Clin Biochem 2012;45:1012-32. http://dx.doi.org/10.1016/j.clinbiochem.2012.08.002.
120. Koseoglu M, Hur A, Atay A, Cuhadar S. Effects of hemolysis interferences on routine biochemistry parameters. Biochem Med (Zagreb) 2011;21:79-85. http://dx.doi. org/10.11613/BM.2011.015.

121. Lippi G, Pavesi F, Cattabiani C, Avanzini P, Pipitone S. Influence of in vitro hemolysis on nucleated red blood cells and reticulocyte counts. Int J Lab Hematol 2013;35:225-8. http://dx.doi.org/10.1111/ijlh.12012.

122. Salvagno GL, Danese E, Lima-Oliveira G, Guidi GC, Lippi $G$. Avoidance to wipe alcohol before venipuncture is not a source of spurious hemolysis. Biochem Med 2013;23:2015. http://dx.doi.org/10.11613/BM.2013.023.

123. Lippi G, Pipitone S, Gennari D, Franchini M. Identification of spurious hemolysis in anticoagulated blood with Sysmex XE-2100 and Siemens Advia 2120. Clin Lab 2012;58:801-4.

124. Lippi G, Pavesi F, Avanzini P, Chetta F, Aloe R, Pipitone S. Development of simple equations for effective screening of spurious hemolysis in whole-blood specimens. Int $J$ Lab Hematol 2015;37:253-8. http://dx.doi.org/10.1111/ ijlh.12277

125. Bonini P, Plebani M, Ceriotti F, Rubboli F. Errors in laboratory medicine. Clin Chem 2002;48:691-8.

126. Carraro P, Plebani M. Errors in a stat laboratory:types and frequencies 10 years later. Clin Chem 2007;53:1338-42. http://dx.doi.org/10.1515/cclm-2014-1053.

127. Simundic AM, Church S, Cornes MP, Grankvist K, Lippi G, Nybo $M$, et al. Compliance of blood sampling procedures with the CLSI H3-A6 guidelines: An observational study by the European Federation of Clinical Chemistry and Laboratory Medicine (EFLM) working group for the preanalytical phase (WG-PRE). Clin Chem Lab Med 2015;53:132131. http://dx.doi.org/10.1515/cclm-2014-1053.

128. Lillo $R$, Salinas $M$, Lopez-Garrigos $M$, Naranjo-Santana $Y$, Gutierrez M, Marin MD, et al. Reducing preanalytical laboratory sample errors through educational and technological interventions. Clin Lab 2012;58:911-7.

129. Lippi G, Salvagno GL, Lima-Oliveira G, Brocco G, Danese $E$, Guidi GC. Postural change during venous blood collection is a major source of bias in clinical chemistry testing. Clin Chim Acta 2015;440:164-8. http://dx.doi. org/10.1016/j.cca.2014.11.024.

130. Lippi G, Salvagno GL, Lima-Oliveira G, Danese E, Favaloro EJ, Guidi GC. Influence of posture on routine hemostasis testing. Blood Coagul Fibrinolysis 2015;26:716-9. http:// dx.doi.org/10.1097/MBC.0000000000000326.

131. Jacob G, Raj SR, Ketch T, Pavlin B, Biaggioni I, Ertl AC, et al. Postural pseudoanemia:posture-dependent change in hematocrit. Mayo Clin Proc 2005;80:611-4. http://dx.doi. org/10.4065/80.5.611.

132. Vuk T, Cipek V, Jukic I. Blood collection staff education in the prevention of venepuncture failures and donor adverse reactions:from inexperienced to skilful staff. Blood transfus 2015:13:338-9. 